\title{
The Role of Heart Team Approach in Penetrating Cardiac Trauma: Case Report and Review of the Literature
}

\author{
Marzia Cottini ${ }^{1}$, MD; Amedeo Pergolini' , MD; Federico Ranocchi ${ }^{1}$, MD; Francesco Musumeci ${ }^{1}$, PhD, FECTS
}

\begin{abstract}
Penetrating cardiac trauma has been increasing in clinical experience and is joined to important morbidity and mortality. A case of a 38-year-old female with history of postpartum depression was reported, admitted to our department for cardiac tamponade due to penetrating self-inflicted multiple stab wound of the chest complicated by rupture of anterior left ventricular wall and traumatic
\end{abstract}

ventricular septal defect. Following the unstable hemodynamic instability, a combined therapeutic strategy was chosen: surgery and transcatheter implantation to correct free wall ventricle damage and traumatic ventricular septal defect, respectively.

Keywords: Wounds, penetrating. Heart septal defects, ventricular. Cardiac Tamponade. Cardiac surgical procedures. Heart injuries. Septal occluder device.

\begin{tabular}{ll}
\hline Abbreviations, acronyms \& symbols \\
\hline CVP $\quad=$ Central venous pressure \\
ECG $\quad=$ Echocardiography \\
TTE $\quad=$ Transthoracic echocardiogram \\
tVSD $\quad=$ Traumatic ventricular septal defect \\
VSD $\quad=$ Ventricular septal defect \\
\end{tabular}

\section{INTRODUCTION}

A very rare and uncommon case of penetrating cardiac injuries was reported, due to multiple self-inflicted stabs in a young female with a history of postpartum depression and causing cardiac tamponade due to free ventricular wall rupture and iatrogenic ventricular septal defect. The particularity of combined therapeutic choices in the same time - surgical drainage of blood pericardial effusion and endovascular closure of traumatic ventricular septal defect (tVSD) with ventricular septal defect (VSD) occluder device - was described.

\section{CASE REPORT}

A case of a 38-year-old female with a history of post-partum depression was presented, referring to our hospital for penetrating self-inflicted multiple stab wounds of the chest. Vital signs of arrival were systolic blood pressure of $80 / 45 \mathrm{mmHg}$, tachypnea (30 breaths/min) with low oxygen saturation (89\%), cyanosis and jugular vein distension (central venous pressure of $15-16 \mathrm{cmH}_{2} \mathrm{O}$ ). The echocardiography (ECG) documented raised ST, J waves. The fast-transthoracic echocardiogram (TTE) revealed a cardiac tamponade (maximum diameter $3.2 \mathrm{~cm}$ ) and a VSD (about 1.5$1.8 \mathrm{~cm}$ from left ventricle side) with ventricular left-right shunt (Qp:Qs=2, Figures 1A to D). Following the critical hemodynamic deterioration, the norepinephrine and epinephrine infusions were started $(0.1 \mathrm{mcg} / \mathrm{kg} / \mathrm{min})$ and the patient was immediately operated. Combined unusual therapeutic strategy has been chosen: surgery for the pericardial effusion drainage and control of the ventricular wall wounds, and transcatheter closure of the tVSD. Median sternotomy and a T-inverted pericardiotomy were performed to remove all clots and pericardial effusion from mediastinum. After the detection of the heart, we found a single left ventricle anterior wall wound, hence we directly closed with
'Department of Heart and Vessels, Cardiac Surgery Unit and Heart Transplantation Center, "S. Camillo-Forlanini" Hospital, Rome, Italy.

This study was carried out at the Department of Heart and Vessels, Cardiac Surgery Unit and Heart Transplantation Center, "S. Camillo-Forlanini" Hospital, Rome, Italy.

No financial support.
No conflict of interest

Correspondence Address:

Marzia Cottini

Department of Heart and Vessels, Cardiac Surgery Unit and Heart Transplantation Center, "S. Camillo-Forlanini" Hospital - Circonvallazione Gianicolense - Rome, Italy E-mail: marzia.cottini@gmail.com 

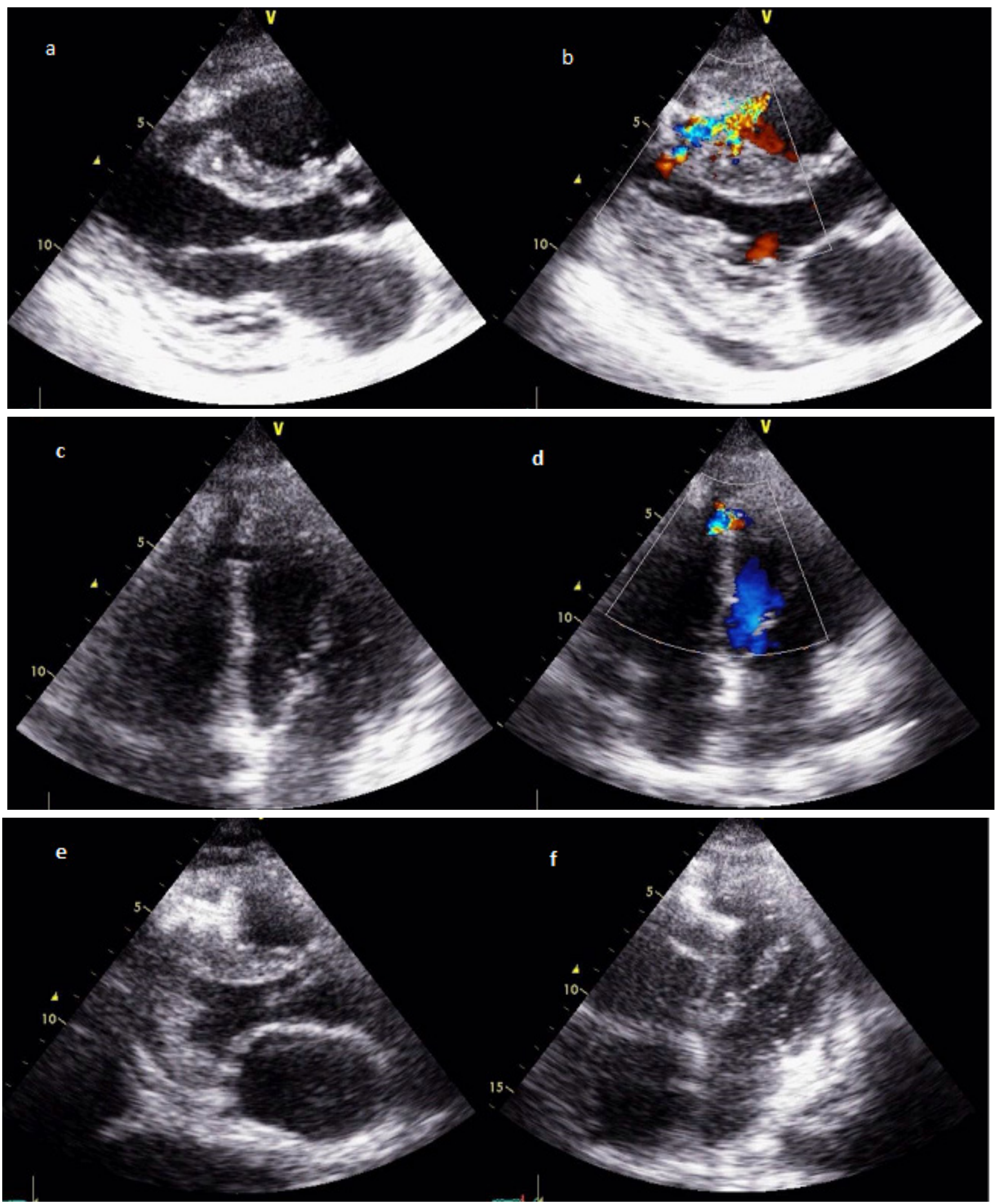

Fig. 1 - Transthoracic echocardiography, parasternal view showing interventricular traumatic defect in the median septum (a), and evidence of left-to-right shunt (b). Transthoracic echocardiography, apical view of iatrogenic interventricular defect (c) and color-doppler image of the L-R shunt (d). Transthoracic echocardiography, longitudinal view of the successful implanting Amplatzer device to close the tVSD (e-f). 

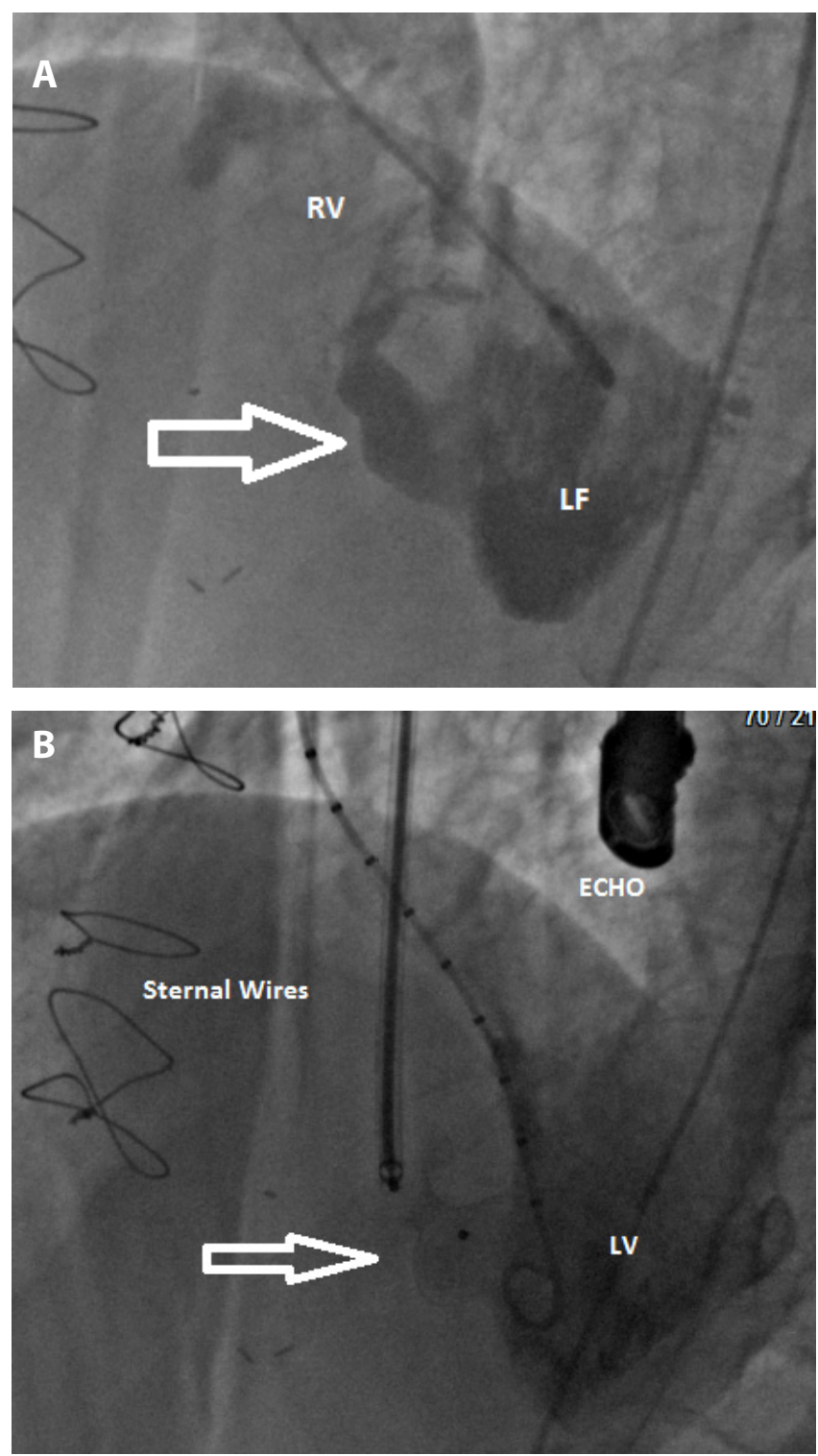

Fig. 2 - Conventional coronary angiography documented traumatic ventricular septal defect (a) and positioning of VSD occluder (white arrow) with good results (b).

a direct suture (3-0 prolene with Teflon pledgets). To complete the treatment, the patient underwent a procedure to position the Amplatzer VSD occluder device (16-mm) by transcatheter way in the same operation time (Figures $1 \mathrm{E}$ to $\mathrm{F}$ and Figure 2B). The procedures were free of complications and the postoperative period was short and uneventfully. She was discharged on the $10^{\text {th }}$ postoperative day with single antiaggregation therapy and was followed-up by psychological support service.

\section{DISCUSSION}

The major cardiac injuries could be blunt or penetrating. Penetrating cardiac trauma has different and several presentations ${ }^{[1-10]}$. The patient could be presented with a stable tamponade (hypotension, elevated central venous pressure [CVP]) or unstable ones (shock with critical hypotension, tachycardia, dyspnoea, raised CVP, pulsus paradoxus with distant heart sounds and impalpable apex). Our patient fitted in the unstable patient type: the decision needed to be made very quickly ${ }^{[7-15]}$. The first step was the diagnostic workout (chest X-ray, ECG, computed tomography scan, TTE) that identify and describe the size, type and setting of the lesion and general assessment. In our case, the patient had a cardiac tamponade due to stab complicated to iatrogenic VSD. Therefore, we decided to proceed with combined therapeutic path in the same time: 1) surgical approach to suture ventricular wound and 2) endovascular approach to close iatrogenic VSD with an occluder device. This case is the first reported in scientific literature because the most of the previous article describe single procedure for closure of VSD with occluder device after surgery or only endovascular approach or first endovascular and then surgery correction, but there are not combined procedures in the same time (Table 1), following some of the most important experience in the literature. According to Degiannis et al. ${ }^{[21]}$, surgical approach could be fundamental and the primary step to control the bleeding, in particularly the best is median sternotomy approach which gives an effective and extensive vision of heart, great vessels, to other structures in the mediastinum and to both pleural cavities ${ }^{[1-9,13-16]}$. On the other hand, left antero-lateral thoracotomy provides rapid access to the right and left ventricles and to the pulmonary artery; this is our approach of choice for emergency room thoracotomy ${ }^{[21]}$. In case of penetrating cardiac injuries complicated by iatrogenic VSD, the combined therapeutic choice with surgery and percutaneous device was described by Argento et al..12], in 2002. Afterwards, only three cases by Berry et al. ${ }^{[13]}$ and Ali et al. ${ }^{[17]}$, with good results (low postoperative recovery, total cardiac function restore without any interventricular septum shunt) were published. The use of minimally surgery (opening, controlling and treating the cause of bleeding) associated with the percutaneous occluder device implantation in penetrating cardiac injuries with iatrogenic VSD may be a complete and safe approach to this trauma patient. The tVSD exclusion by percutaneous device avoided long surgical timing hence less invasiveness, no cardiopulmonary bypass, less anesthesia time and recovery time.

\section{CONCLUSION}

The combined therapeutic choice of surgery and interventional approach in case of penetrating cardiac trauma with limited tVSD is indicated and optimal for rapid clinical stabilization.

The rapid and early diagnosis associated with an organized and available cardiac staff (interventional cardiologists and cardiac surgeons) may be a productive collaboration.

\section{ACKNOWLEDGEMENTS}

We thank Dr. Violini and his staff for the VSD occluder implantation in our patient which greatly improved the case. 
Table 1. Review of previous ventricular septal defect (VSD) after cardiac wound stab described in scientific literature and their treatments. The traumatic VSD was diagnosed immediately, deferred VSD diagnosis was not considered.

\begin{tabular}{|c|c|c|c|c|c|c|}
\hline Author & Year & Type of Paper & Patient & Gender & Complication & Therapeutic choice \\
\hline Lui et al..1] & 1965 & $C R$ & 1 & Male & Cardiac tamponade & Surgery \\
\hline Pejaković \& Mileusnić[2] & 1967 & $C R$ & 1 & Male & Cardiac tamponade & Surgery \\
\hline Kieny et al. ${ }^{[3]}$ & 1975 & $C R$ & 1 & Male & Cardiac tamponade & Surgery \\
\hline Asfaw et al. ${ }^{[4]}$ & 1975 & $R L$ & 12 & Male & $\begin{array}{c}\text { HF, injury of tricuspid } \\
\text { valve, injury of left anterior } \\
\text { descending coronary artery }\end{array}$ & Surgery \\
\hline Bande et al. ${ }^{[5]}$ & 1980 & $C R$ and $R L$ & 1 & Male & Cardiac tamponade & Surgery \\
\hline Bryan et al..6] & 1988 & $C R$ & 1 & Male & Cardiac tamponade & Surgery \\
\hline Voronov et al. ${ }^{[7]}$ & 1989 & $C R$ & 1 & Male & Cardiac tamponade & Surgery, suture \\
\hline Take et al. ${ }^{[8]}$ & 1993 & $C R$ & 1 & Female & Rupture of papillary muscle & Surgery \\
\hline Carvalho et al. ${ }^{[9]}$ & 1994 & $C R$ & 1 & Male & Hemothorax & Surgery, patch suture \\
\hline Doty et al. ${ }^{[10]}$ & 1999 & $C R$ & 1 & Male & Tricuspid valve injury & Surgery \\
\hline Gölbasi et al. ${ }^{[11]}$ & 2001 & $C R$ & 1 & Male & Cardiac tamponade & Surgery, suture \\
\hline Argento et al. ${ }^{[12]}$ & 2002 & $C R$ & 1 & Male & Cardiac tamponade & $\begin{array}{c}\text { Thoracotomy and } \\
\text { percutaneous device }\end{array}$ \\
\hline Berry et al.. ${ }^{[13]}$ & 2006 & $C R$ & 1 & Male & Cardiac tamponade & $\begin{array}{c}\text { Surgery and } \\
\text { percutaneous device }\end{array}$ \\
\hline Topaloglu et al. ${ }^{[14]}$ & 2006 & $C R$ & 1 & Male & Cardiac tamponade & Surgery \\
\hline Choi et al. ${ }^{[15]}$ & 2008 & $C R$ and $R L$ & 1 & Male & Atrioventricular valves rupture & Surgery \\
\hline Antoniades et al. ${ }^{[16]}$ & 2011 & $C R$ & 1 & Female & $\begin{array}{c}\text { Pneumothorax and cardiac } \\
\text { tamponade }\end{array}$ & Surgery \\
\hline Ali et al. ${ }^{[17]}$ & 2013 & $C R$ & 1 & Male & Cardiac tamponade & $\begin{array}{c}\text { Surgery and } \\
\text { percutaneous device }\end{array}$ \\
\hline Caffery et al. ${ }^{[18]}$ & 2014 & $C R$ & 1 & Male & Hemothorax & $\begin{array}{c}\text { Percutaneous device } \\
\text { then surgery }\end{array}$ \\
\hline Tang et al..[19] & 2016 & $C R$ & 1 & Male & Congestive heart failure & $\begin{array}{c}\text { Percutaneous device } \\
\text { then surgery }\end{array}$ \\
\hline Kharwar et al. ${ }^{[20]}$ & 2016 & $C R$ & 1 & Male & Cardiac tamponade & Percutaneous device \\
\hline $\begin{array}{l}\text { Cottini et al. } \\
\text { (reported case) }\end{array}$ & 2018 & $C R$ and $R L$ & 1 & Female & Cardiac tamponade & $\begin{array}{c}\text { Surgery and } \\
\text { percutaneous device }\end{array}$ \\
\hline
\end{tabular}

$\mathrm{CR}=$ case report; $\mathrm{RL}=$ review of the literature; $\mathrm{HF}=$ heart failure

\section{Authors' roles \& responsibilities}

MC First Author, revision and corresponding author; final approval of the version to be published

AP Writting and revision; final approval of the version to be published

FR Revising; final approval of the version to be published

FM Revised critically; final approval of the version to be published

\section{REFERENCES}

1. Lui AH, Glas WW, Bercu BA. Stab wound of the heart with tamponade and interventricular septal defect. Report of a case. JThorac Cardiovasc Surg. 1965;49:517-22.

2. Pejaković S, Mileusnić S. Interventricular defect of the septum caused by a stab wound of the heart. Srp Arh Celok Lek. 1967;95(1):75-9.

3. Kieny R, Wolff F, Gross A, Mantz JM, Kurtz T, Kieny MT. Post-traumatic interventricular communication. Closure under extracorporeal circulation. Arch Mal Coeur Vaiss. 1975;68(1):97-103.

4. Asfaw I, Thoms NW, Arbulu A. Interventricular septal defects from penetrating injuries of the heart: a report of 12 cases and review of the literature. J Thorac Cardiovasc Surg. 1975;69(3):450-7. 
5. Bande A, Pisano GF, Sanna A, Scano F, Binaghi F. Interventricular communication secondary to a penetrating heart wound. A case description; a review of the literature. Minerva Cardioangiol. 1980;28(78):543-6.

6. Bryan AJ, Angelini GD, Breckenridge IM. Spontaneous closure of a traumatic interventricular septal defect following a penetrating chest injury. Thorac Cardiovasc Surg. 1988;36(3):172-3.

7. Voronov AA, Kuksinskii VE, Il'in AS. Surgical treatment of a traumatic defect of the interventricular septum after a knife wound of the heart. Grudn Khir. 1989;5:90-1.

8. Take A, Yamaguchi T, Horimi H, Kato M, Hasegawa T, Kimura S. Blunt cardiac trauma resulting in ventricular septal perforation and mitral regurgitation due to papillary muscle rupture: a case report. Nihon Kyobu Geka Gakkai Zasshi. 1993;41(1):119-25.

9. Carvalho AC, Echeverria NG, Gonçalves R, Telles CA, Andrade JC, Buffolo E. Late development of congestive heart failure in interventricular communication caused by penetrating wound, with pulmonary hypertension resolution after surgical correction. Arq Bras Cardiol. 1994;62(2):119-21.

10. Doty JR, Cameron DE, Elmaci T, Salomon NW. Penetrating trauma to the tricuspid valve and ventricular septum: delayed repair. Ann Thorac Surg. 1999;67(1):252-3.

11. Gölbaşi Z, Ciçek D, Uçar O, Kaya D, Keleş T, Ciçekçiolu H, et al. Traumatic ventricular septal defect and mitral insufficiency after a Kebab's shish wound to the chest. Eur J Echocardiogr. 2001;2(3):203-4.

12. Argento G, Fiorilli R, Del Prete G. A rare case of a post-traumatic intraventricular defect. Ital Heart J Suppl. 2002;3(3):352-4.
13. Berry C, Hillis WS, KnightWB. Transcatheter closure of a ventricular septal defect resulting from knife stabbing using the Amplatzer muscularVSD occluder. Catheter Cardiovasc Interv. 2006;68(1):153-6.

14. Topaloglu S, Aras D, Cagli K, Ergun K, Deveci B, Demir AD, et al. Penetrating trauma to the mitral valve and ventricular septum. Tex Heart Inst J. 2006;33(3):392-5.

15. Choi JS, Kim EJ. Simultaneous rupture of the mitral and tricuspid valves with left ventricular rupture caused by blunt trauma. Ann Thorac Surg. 2008;86(4):1371-3.

16. Antoniades L, Petrou PM, Eftychiou C, Nicolaides E. Penetrating heart injury resulting in ventricular septal defect. Hellenic J Cardiol. 2011:52(1):71-4.

17. Ali TA, Fatimi SH, Hasan BS. Transcatheter closure of a traumatic ventricular septal defect using an Amplatzer ${ }^{\mathrm{TM}}$ atrial septal occluder device. Catheter Cardiovasc Interv. 2013;82(4):569-73.

18. Caffery T, Robinson D, O'Neal H, Kahn A, Thurston S, Musso M. Delayed detection of a ventricular septal defect following penetrating trauma. J La State Med Soc. 2014;166(6):239-41.

19. Tang L, Tang JJ, Fang ZF, Hu XQ, Shen XQ, Zhou SH. Severe mechanical hemolysis after transcatheter closure of a traumatic ventricular septal defect using the Amplatzer atrial septal occluder. Int Heart J. 2016;57(4):519-21.

20. Kharwar RB, Madan T, Thakkar B, Shukla A, Deshmukh J. Percutaneous device closure of post-traumatic ventricular septal rupture. JACC Cardiovasc Interv. 2016;9(17):1848-50.

21. Degiannis E, Bowley DM, Westaby S. Penetrating cardiac injury. Ann R Coll Surg Engl. 2005;87(1):61-3. 